\title{
El cerebro humano aplicado a la creatividad
}

José Antonio Jáuregui Oroquieta

Arbor CLXV, 649 (Enero 2000), 109-119 pp.

\section{El cerebro rebelde}

Hoy las ciencias sociales están tomando unos nuevos derroteros, desde que han entrado en escena los etólogos o sociobiólogos. Edward O. Wilson acuñó en la década de los años setenta una palabra nueva: SOCIOBIOLOGY ${ }^{1}$. Esta palabra levantó muchas ampollas - sobre todo en la piel ideológica- y, como el escándalo tiene mucho más interés que la norma cumplida, apareció Wilson en la hornacina del altar de las portadas del Time y de otras revistas de esta naturaleza ¿La nueva pregunta es: hemos de hablar de sociología o de sociobiología? ¿La estructura social está diseñada por un plan biológico y genético? ¿Están el hombre y el mono inmersos en unas estructuras biológicas de sus respectivas sociedades como el tren en sus railes?

Toda mi obra (y específicamente mi libro Cerebro y Emociones: El Ordenador Emocional) está encaminada a responder a estas preguntas. La clave de la estructura social está en el cerebro en un orden muly importante de cosas.

El Profesor Thorpe ${ }^{2}$, un pensador original, desde las premisas de la etología hizo un experimento de gran calado en estos temas en su laboratorio de la Universidad de Cambridge. Apenas salidos del huevo unos pájaros llamados pinzones (en inglés chaffinch) fueron colocados por el profesor Thorpe en tres habitaciones distintas e incomunicadas. Un pajarillo pinzón nunca escuchó ningún canto de pájaros. Este pajarillo nunca cantó. Un pajarillo pinzón escuchó el canto de jilgueros y de canarios. Nunca cantó. Un tercero escuchó el canto de los pinzones. Este fue el único pajarillo pinzón que cantó. Repitió el experimento varias veces, obteniendo siempre el mismo resultado. El idioma de 
los pinzones no se trasmite por vía genética sino por aprendizaje, como ocurre con el francés o con el castellano. Pero, si nos fijamos bien, este experimento nos revela un fascinante mundo tan biológico como social. El cerebro tiene dos programas: un hardware o disco duro por el que el cerebro graba automáticamente ciertos idiomas sociales pero no otros y un software, o sea, los programas sociales que se van grabando inconsciente y automáticamente.

El cerebro es una gran herramienta a la vez biológica y social y por tanto biosocial. Estos son en mi opinión los cimientos de las nuevas ciencias sociales. Pero el cerebro de la abeja, de la araña o del mono es un cerebro obediente, mientras que el cerebro del hombre es un cerebro rebelde, un cerebro disconforme, un cerebro descontento, Podemos encontrar una pista interesante al tema que nos ocupa en la primera frase de la Metafísica de Aristóteles: Пó $v \tau \varepsilon s$

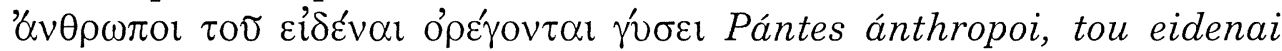
orégontai fisei: «Todos los hombres se sienten inclinados a conocer, a idear, a crear nuevos conceptos». O bien «Todos los hombres sienten sed de conocer, de idear, de crear nuevos conceptos, de cuestionarse, de hacerse nuevas preguntas». Eíféval, Eidenai, es un verbo derivado

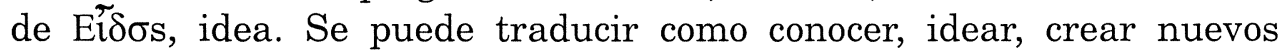
conceptos, hacerse nuevas preguntas, no conformarse con el orden establecido.

Un programa cerebral, el programa de la rebelión, marca una frontera genética y biosocial entre la sociedad humana y todas las demás sociedades animales, entre el hombre y el mono. Aristóteles nos habla - si nos fijamos bien- de dos mundos: el mundo de los sentimientos (orégontai: sentir ganas de) y el mundo de las ideas (eidenai: idear, crear nuevas ideas).

No se devanaría los sesos el empresario ni sudaría el obrero si no sintieran la sacra auri fames: el hambre del oro, la sed del dinero. No beberíamos agua, si no nos activara el cerebro el densitómetro emocional de la sed.

Sostengo en mi libro Cerebro y Emociones: El Ordenador Emocional, cómo el cerebro es un marionetero que mueve a su marioneta -tú, lector, y yo, escritor- con los hilos invisibles de los sentimientos. El cerebro activa un repertorio de densitómetros emocionales en una escala de cero a cien, indicando y empujando al sujeto a realizar una serie de tareas precisas: ganas de beber para que beba, ganas de hacer el amor, para que realice este trabajo, ganas de vivir para que viva e, incluso, ganas de morir para que se suicide. El cerebro mediante el E-mail de los sentimientos informa al sujeto de una tarea que debe 
realizar para que funcione alguno de los sistemas orgánicos (el digestivo, el térmico, el respiratorio etc.) o de los sociales (sistema económico, sistema ético, sistema de parentesco etc.). Si el cerebro no informara al sujeto de cuándo y cuánto debe comer o de beber el sujeto no realizaría ninguna de estas tareas. Pero el cerebro además de informar al sujeto de una tarea que debe realizar, le presiona con la palanca de los sentimientos: «Si bebes agua, dejaré de incordiarte con las ganas de beber agua»; «si haces el amor, dejaré de incordiarte con las ganas de hacer el amor».

El cerebro, desde el programa genético y biosocial de la innovación, de la creatividad y de la rebeldía, activa el densitómetro emocional del eidenai: "Si se te ocurre algo, si creas algo nuevo, dejaré de incordiarte». Aquí está la clave de la creatividad.

Dijo Unamuno ${ }^{3}$ que, si las piezas de ajedrez tuviesen conciencia, se atribuirían erróneamente a ellas mismas los movimientos en el tablero ¿Quién pinta las Meninas Velázquez o el cerebro de Velázquez? ¿Quién descubre la ley de la relatividad Albert Einstein o el cerebro de Albert Einstein? ¿Quién escribe Hamlet, William Shakespeare o el cerebro de William Shakespeare?

El cerebro tiene dos llaves genéticas en riguroso monopolio: la llave de la activación y desactivación de la conciencia del sujeto y la llave de la activación y desactivación de todos y cada uno de los densitómetros emocionales. El cerebro es un perfecto anestesista: todos los días, cuando menos pensamos, nos desenchufa como a una bombilla y nos introduce en el mundo de la nada mental y emocional (sueño, coma, muerte). Todos los días nos enciende como a una bombilla y nos trae al mundo de la conciencia: el mundo de idear y de sentir.

Pero el sujeto, si bien está sujeto (sub-iectus: estar debajo de, sometido a) a estas dos llaves del cerebro, tiene también un cometido de libertad, de innovación y de creatividad. Ramón y Cajal intuyó la capacidad de crear libremente del sujeto al afirmar: "Cada uno de nosotros puede, si se lo propone, ser el escultor de su propio cerebro» ${ }^{4}$. Velázquez, él mismo, el sujeto consciente, puede moldear y esculpir su propio cerebro y puede intervenir en la creación del cuadro de Las Meninas. Einstein al alimón con su cerebro, descubre e inventa una fórmula nueva y una teoría que no existía.

Estos son los elementos del Homo Creativus, del animal creativo:

1. El programa cerebral de la innovación. Siente el hombre desde niño una cierta disconformidad con su propia sociedad, con su propia familia, con sus propios juguetes, con todo el mundo que le rodea.Este programa cerebral tiene varias vertientes: por una parte el cerebro 
permite al sujeto el tomar conciencia de sí mismo, de su vida $-\mathrm{y}$ sobre todo de su muerte- y de su propia sociedad como no le permite al mono ni a la abeja. Mi hija Maite con seis años, tras asistir al entierro de su abuela con la que jugaba todos los días, se pregunta a sí misma en la cama esa noche en mi presencia: «¿Por qué nos tenemos que morir todos?». Y sin darme tiempo a que le responda, ella misma intenta contestar: «Claro, el mundo se llenaría de gente. No cabríamos todos, si no nos muriéramos» ${ }^{5}$.

2. Otra vertiente de este programa del cerebro creativo es el tedio, el aburrimiento, la saciedad. Llega Beethoven y escucha la música de Bach y de Mozart. Le gusta esta música pero empieza a aburrirle. Hay que crear composiciones nuevas, distintas, innovadoras. Le faltan a la orquesta varios instrumentos. Beethoven añade varios instrumentos nuevos y crea una orquesta mucho más grande y sonora que las que conocieron Vivaldi y Mozart. "No pensará Usted, Sr. Beethoven, que estas obras son música», le preguntó desde la soberbia cerril Clementi refiriéndose a los cuartetos Rasumovsky. «Es que no son para Usted», le replicó Beethoven. "Son para una época posterior» ${ }^{6}$. Puede parecer esta respuesta de Beethoven un desplante soberbio en el ruedo humano del juego a tener razón - tan poco racional a veces-, pero las épocas posteriores han dado la razón a Beethoven.

3. El contrapunto del programa creativo del cerebro es el freno biosocial del ridículo. No sabe un mono lo que es «hacer el ridículo». El ridículo es una multa genética y biosocial instalada en el ordenador cerebral para castigar al que infringe las reglas del juego ${ }^{7}$. Es un freno genético previsto frente al acelerador del animal rebelde, disconforme y creativo. Fue Emile Durkheim en Las Reglas del Método Sociológico quien nos señaló un importante «hecho social»: «Todo innovador sufrirá persecución» ${ }^{8}$. Durkheim quiere transmitirnos un descubrimiento suyo (innovador): los hechos sociales son modos de pensar, sentir y actuar que se imponen desde fuera con un poder coercitivo por el que lo controlan. Para demostrar cómo un hecho social - sea el idioma francés- se impone a un individuo - un ciudadano de Francia- nos llama la atención sobre un hecho social: el innovador es atacado con las piedras del ridículo por su sociedad.

En efecto se crean unas reglas de juego en una determinada sociedad tanto en el mundo de la ciencia, como en el de la música, como en el de la poesía, como en el de la política, como en el de la iglesia. Beethoven se siente empujado por las ganas de crear, de innovar tanto en los cuartetos como en las sinfonías. Pero los clementis, al escuchar los cuartetos Rasumovsky, se topan con una composición que infringe 


\section{El cerebro humano aplicado a la creatividad}

las reglas del juego vigentes. El cerebro desencadena las ganas de reir, de ridiculizar «aquellas mamarrachadas» y a Beethoven «que se ha vuelto loco».

El plan genético ha previsto un juego que no se da en otras especies: el juego entre el que infringe las reglas del juego y la sociedad que defiende las reglas del juego con el castigo del ridículo y con otras multas (encerrarlo en un manicomio, quemarlo en un pira junto a sus libros etc. etc.). Semmelweiss ${ }^{9}$, un médico vienés, se percató de que los médicos que hacían autopsias, al tocar a las mujeres que iban a dar a luz sin lavarse las manos, las contagiaban de septicemia y morían. En un congreso científico aconsejó a estos médicos que se lavaran las manos. «¿Nos está llamando guarros este imbécil? ¿Nos está llamando criminales?». Aquellos médicos certificaron «médicamente» que Semmelweis estaba loco y lo encerraron en un manicomio donde murió. Hoy se considera a Semmelweiss un "mártir de la ciencia» ¿No fue Picasso apedreado con las piedras del ridículo cuando pintó Las Bañistas de Aviñón? ¿No obligaron a Galileo a jurar que la tierra estaba inmóvil y que era el sol el que giraba al rededor de la tierra?

4. Un cuarto elemento a tener en cuenta es la libertad del sujeto innovador. En un importante orden biosocial de cosas el sujeto está «sujeto» al cerebro como una marioneta manipulada por un marionetero. Pero en otro orden de cosas, Beethoven, Mendelweiss o Galileo Galilei, él mismo, o sea, el sujeto, ese misterioso fantasma del castillo somático que ni se ve ni se toca, puede elegir y tiene que elegir entre dos rutas diametralmente opuestas: Por un lado el cerebro empuja a Beethoven a componer una música que se sale de los esquemas al uso, que infringe las reglas del juego. Tiene que seguir el duro lema de Benito Pérez Galdós ${ }^{10}$ : «Si quieres que tus escritos permanezcan, escribe como si ninguno de tus contemporáneos fuera a leerte». Es el lema opuesto a la peste que nos invade del pest-seller ${ }^{11}$ : destrozar la calidad para vender más. Por otra parte el mismo cerebro desde le programa de respetar las reglas del juego sociales imperantes le habla siempre con el lenguaje del cerebro: el emocional: «Ludwig: si compones estos cuartetos, prepárate a hacer el ridículo: los clementis se reirán de tí: ¿No pensará Usted, claro, que esto es música verdad? Ja,ja,ja,ja,ja. $\mathrm{Si}$ quieres tener éxito, si quieres que te aplaudan los clementis, si quieres tener éxito en el mercado del pest-seller, dales gustirrinín a los clementis. Al fin y al cabo, aunque la posteridad te aplauda, tú no estarás ahí para saborear la miel de los aplausos».

Ahí todo Beethoven se la juega. No es libre Galileo de ser sometido a los zarpazos emocionales de dos fieras que se lo disputan desde su 


\section{José Antonio Jáuregui Oroquieta}

propio cerebro. Las batallas emocionales se libran dentro del sujeto: Solo Galileo, solo el sujeto vive su procesión emocional: «la procesión va por dentro». Nadie sabe a qué presiones emocionales somete el cerebro a todo ser humano que quiera innovar algo en cualquier campo social: el artístico, el científico o el técnico. Podría Van Gogh haber elegido el camino de halagar a sus contemporáneos; podría Mozart haber halagado a los salieris, al Emperador y a su corte de aduladores; podría Cristo haberse callado y no haber intentado romper la regla del juego del ojo por ojo y diente por diente; podría Sócrates haberse tenido su lengua callada, sin desempeñar el papel de tábano ético que estimule al caballo grande y noble, pero pesado del Estado $\left(\pi \sigma \sigma^{\prime} \lambda \mathrm{s}\right)^{12}$; podría el innovador respetar las reglas del juego y así se ahorraría el hacer el ridículo, el ser encerrado o ejecutado con alguna cicuta.

Puede el ser humano, el sujeto, elegir una u otra ruta. Carlos Marx afirmó que la lucha de clases es el motor de la historia ${ }^{13}$. Para Marx el hombre es un HOMO AURIFAMELICUS, un hombre que juega al juego de tener más, porque sabe que el rico puede viajar en primera con un saludo obsequioso de azafata saboreando viandas exquisitas y especialmente las delicatessen de sentirse viajero de "primera» o de "grand class», frente al que viaja en «Business class» con un saludo de azafata de clase media, espacio de clase media y comida de clase media y frente al viajero de «Economy Class» o «Clase Turista» sin mantel de paño, con un saludo de azafata de clase turista, un miniespacio de clase turista y unas bazofias recalentadas de clase económica. Pero no es el juego de clases el único motor de la historia. Uno de los grandes motores de la historia es el innovador. Somos la especie más innovadora. No siempre ha habido aviones ni internet. No siempre se ha operado con rayos láser. En todos los dominios sociales los innovadores han sido grandes motores de la historia y de la sociedad, incluyendo al propio Marx que creó a los «marxistas», movidos sobre todo por él, por la fe en un nuevo moisés que les llevaría y nos llevaría a todos al paraíso de la sociedad sin clases, justa y solidaria.

5. Un quinto elemento en el proceso creativo es el precio que hay que pagar por la innovación. Al haber previsto el plan genético y biosocial que la sociedad humana no sea como la de las abejas, sino una sociedad en un orden de cosas dejada al libre arbitrio, elección y creatividad de los marx, los hitler, los galileo, los mozart, los nerón, los einsteins, los kafkas, los mercaderes del pest-seller, las prostitutas, las mafias, los tomásmoro, los budas y budistas, los resultados son maravillosos y la cosecha de ciencia, tecnología, arte y solidaridad es ubérrima. Pero también esta creatividad, esta rebeldía, esta inconformidad con 
la realidad tiene un precio que hay que pagar. Humanum est errare: el error es una seña de identidad humana. Este es uno de los precios que hay que pagar. No solamente los innovadores han de apechugar con las risitas de sus contemporáneos (ridiculum en latín quiere decir risita) y sufrir todo género de vejaciones, torturas y tal vez muerte ritual, sino que los marxistas y los hitlerianos podrán «enfrentarse a muerte» en todos los sentidos de esta expresión, todos a la búsqueda de la sociedad utópica (ou-topos: el no lugar), la isla del no-lugar. Tanto en el campo político como en el artístico se crean equipos, facciones, capillas y sectas que se insultan, se odian, se atacan y a veces se matan. En ciertos museos aparecen toda suerte de objetos sucios y rotos como el non plus ultra del arte moderno. Algunos denominados post-modernos, como nuevos iconoclastas, la han emprendido contra todo dogma, toda tesis, toda verdad, venerando un nuevo totem: el totem de todo vale, sin haber leído a Durkheim que ya enunció que los adalides del «pensamiento libre» eran tan dogmáticos y cerrados en su jaula mental como aquellos a los que atacaban ${ }^{14}$.

Por viajar en primera -en avión y en todas las demás estancias del apartheid económico del viaje de la vida- algunos «científicos o «artistas ( $m a$ non troppo) venden su alma artística o científica a cualquier mefistófeles que les pague bien «¿Cómo va a titular este cuadro?», preguntó una dama estadounidense a Picasso. «Mirándola a Usted, no se si titularlo dos millones o tres millones de dólares», replicó el pintor del Guernica. Esta anécdota, probablemente apócrifa, revela una tentación de todo Picasso: pintar una sandez en el mercado del pest-seller para conseguir un buen puñado de dólares de una cretina de tomo y lomo.

6. Un último elemento a tener en cuenta es la lenta programación cerebral. "Tienes que dedicarte cuerpo y alma como un monje asceta medieval al menos veinticinco años a dibujar, para poder desempeñar con un mínimo de verdad y de honradez el oficio de pintor», me dijo en su estudio de La Jolla, San Diego (California), Sebastian Capella, un pintor de este siglo mucho menos conocido y venerado que Antoni Tapies, pero al que, en mi opinión, Velázquez y Rembrandt considerarían como a un respetado colega suyo. Andrés Segovia, con quien compartí durante diez años pan, mesa, sobremesa y amistad me dijo: «Se necesitan cinco minutos de inspiración, pero noventa y cinco de transpiración». No puede Sebastián Capella pintar los cuadros maravillosos que pinta, sin que su cerebro tenga un programa de manejar el pincel edificado durante veinticinco años. No puede Andrés Segovia tocar la Chacona de Bach hasta lograr embelesar a Henri Bergson y a una audiencia 
bachiana, sin haberse dedicado cuerpo y alma, horas y horas, años y años a ensayar una y mil veces los mismos pasajes.

El cerebro está genéticamente programado para crear programas gota a gota, día a día, mes a mes, año tras año. El sujeto debe de sacrificar su vida a programar su cerebro, si quiere llegar a ser un Velázquez, un Aristóteles (que estuvo durante veinte años seguidos escuchando a su maestro Platón en la Academia), un Juan Sebastián Bach. El cerebro se programa lentamente. Un Rembrandt tiene en su cerebro una verdadera Catedral gótica de Milán edificada en su cerebro hora a hora y año tras año. Una vez que el cerebro tiene un programa tan elaborado, puede Shakespeare escribir o Mozart componer "como quien lava». La metáfora de las musas que inspiran es una intuición atinada. Es el cerebro el que dicta al escritor o «inspira» al pintor al científico, al poeta o al compositor. El sujeto debe de esculpir su cerebro - frase certera y profunda de Ramón y Cajal-. Debe de tener una paciencia franciscana y una dedicación de monje asceta para ensayar, ensayar y ensayar hasta que el cerebro haya adquirido ese programa. Cuando Bach compone la Misa en Sí Menor, es él el sujeto el que ha decidido componer esta Misa y es él el que ha elegido el sí menor. Pero es su cerebro programado con un sistema grecolatino-eurocristiano ${ }^{15}$ el que le va dictando la Misa. De repente "se le ocurre una melodía» - es decir su cerebro le sirve en bandeja de plata esta melodía- A veces apenas puede seguir con sus manos escribiendo notas en el pentagrama ya que la velocidad del dictado del cerebro es muy rápida. Son los mejores «momentos de inspiración». Si el sujeto no recibe esos dictados, si «fuerza» su pluma o su pincel, cuando «no le sale nada» y si el sujeto no ha sentido una profunda emoción al escuchar esa melodía dictada por el cerebro, esa melodía será «artificial», «forzada», falta de inspiración.

Si el sujeto no está activado - Bach está dormido, borracho o en estado de coma-, su cerebro no puede componer la Misa en Si Menor. Si el artista ha tenido un accidente cerebral y sufre «amnesia grave», todo el programa grabado durante veintitantos años sigue archivado en el cerebro, pero por una avería traumática, no puede el sujeto tener acceso a ese archivo. Puede el sujeto sentirse bien y perfectamente consciente, pero puede haber perdido el acceso a ciertos archivos de su ordenador cerebral. En algunos casos, al cabo de cierto tiempo, vuelve a recuperar el sujeto el acceso parcial o pleno a esos archivos.

La obra creativa es un toreo al alimón entre el sujeto y su cerebro. 


\section{El cerebro humano aplicado a la creatividad}

\section{Notas}

1 Debemos a Augusto Comte la palabra Sociología, a Aristóteles Economía (la norma o medida de la casa: ỡ Edward O. Wilson Sociobiología. Los forjadores de estas palabras en la fragua de su razón y de su imaginación han sido grandes motores en el desarrollo de estas áreas de conocimiento.

2 THORPE, W.H. (1963): Learning and Instinct in Animals. London, Methuen.

3 Unamuno, Miguel de (1993): Del Sentimiento Trágico de la Vida, Altaya, Barcelona p. 131

4 Antonio LóPEz ABAD, un brillante estudiante mío de la Universidad Complutense, me señaló esta frase que está esculpida en letras enormes en el vestíbulo del Hospital Ramón y Cajal de Madrid.

5 Los etólogos o sociobiólogos sostienen que la cultura no es algo privativo de la sociedad humana. También los simios tienen cultura. Una de las pruebas que aducen para sostener esta tesis nueva y revolucionaria en las ciencias sociales es el experimento realizado por etólogos japoneses en una pequeña isla del Pacífico llamada Koshima. Los etólogos observaban diariamente el comportamiento de una tropa de macacos. Un día les echaron patatas mezcladas con arena. Todos limpiaron las patatas con las manos. Pero una mona joven - de dos años - a la que llamaron IMO las limpió en el agua. Los monos más jóvenes empezaron a imitarla. Los monos de más edad y jerarquía social despreciaron la innovación. Otro día les dieron trigo mezclado con arena. La mona Imo echó al algua el trigo mezclado con arena y, al flotar el trigo y hundirse la arena, logró un nuevo invento que fue adoptado por toda la sociedad con la excepción de los monos ancianos y jerarcas. Cabe por tanto la innovación, el invento, el descubrimiento de algo nuevo en la sociedad de los simios y la posterior adopción social. Si la cultura requiere innovacion, concluyen los etólogos, los monos y otros animales tienen cultura.

En esta nueva encrucijada científica y a la luz de estos experimentos científicos pioneros, debemos cambiar el discurso o paradigma social: en vez de sostener que solo la sociedad humana tiene cultura debemos preguntarnos dónde reside la frontera genética y biosocial entre la cultura de la mona Imo y de su sociedad simia y la cultura de Cristo, Marx, Buda, Sócrates, Rembrandt, Fidias, Picasso y de su sociedad humana.

6 Grout D. J. y Palisca C.V. (1984): Historia de la Música Occidental, 2, Alianza, Madrid, p. 648.

7 JÁUREGUI, J.A.: Cerebro y Emociones: El Ordenador Emocional (1998), Maeva, Madrid pp. 175-200, Leyes Emocionales de la Risa y del Lenguaje. Eduardo S. Jáuregui ha defendido una tesis doctoral en el Instituto Universitario de Florencia sobre este tema, todavía sin publicar, Henri Bergson fue el pionero en este campo sociológico/psicológico en su breve pero incisivo ensayo sobre la risa: Essai sur le Rire.

8 DuRkheim, Emile (1994): Las Reglas del Método Sociológico, especialmente el capítulo I - ¿Qué es un hecho social?-, pp 56-101

9 Ignác FÜloP SEMMELWEISS (1818-1865): fue un médico húngaro que ejerció su profesión en Viena. En 1850 presentó su revolucionario método de higiene en la Academia de las Ciencias de Viena, salvando muchas vidas humanas en el futuro gracias a su método innovador, aunque él tuvo que perder su prestigio, su cátedra, su trabajo y su libertad. Aquí radica una de las fronteras culturales con la sociedad de la mona Imo. 
10 No encuentro en mi biblioteca los dos tomos de la obra completa de nuestro eminente escritor canario, donde tengo señalada esta cita. Doy la cita tal como la tengo archivada en mi "ordenador cerebral». Por tanto, non ipsissima verba.

11 En una lección que impartí en la Universidad de Padua sobre «Cultura Europea» invitado por el Profesor Antonio Papisca dije: «Junto a esta Cátedra de Galileo Galilei, verdadera reliquia del Templo de la Inteligencia» - en expresión unamuniana-, quiero iniciar una campaña contra el pest-seller. Hay una falta de ortografía ética y estética en la expresión moderna del best-seller: se escribe con b-best- pero se debe escribir con $\mathrm{p}$ - pest-, peste. Se trata, en efecto, de destruir la calidad en la carne hormonada de pollos, en el alimento inadecuado que ha creado las mad-cows, vacas locas para vender más - best-seller - y también se trata de destrozar la calidad literaria, científica, cinematográfica y todas las demás para vender más. Es la peste del pest-seller contra la que en nombre de Galileo, Mozart y Van Gogh -inter alios- debemos levantar nuestra voz en la Academia y en los medios de comunicación tan subyugados a los bajísimos "niveles de audiencia».

12 Platón, Diálogos (1993), Apología, Editorial Gredos, Madrid, p. 169

13 «Toda la historia de la sociedad humana hasta el día es una historia de lucha de clases" Esta es la primera frase del Manifiesto Comunista. Es la tesis central de Marx: lo que mueve la sociedad y la historia es una lucha y esta lucha es una lucha de equipos económicos: las clases. Sin embargo uno de los juegos más duros, feroces y a veces (muchas, demasiadas) un juego a muerte se da entre el innovador y su sociedad. No es un juego económico, sino un juego de los innovadores contra los inmovilistas. Es un juego apasionado y apasionante -incluso racional y a veces hasta razonable- de ideas y de ideales.

14 DuRKheIM, Emile (1994): Las Reglas del Método Sociológico. Unamuno acuñó la expresión "fanáticos del racionalismo" (p. 103, Unamuno, 1993) señalando a los que tienen una fe ciega en la razón hasta convertirla en una diosa a la que debemos adorar. Los postmodernos, iconoclastas de todo dogma, no se hacen cargo de que han erigido un nuevo icono que es intocable y venerable. Ya se percató Unamuno, con su mente aguda e incisiva, de la contradicción de los iconoclastas de la primera etapa del cristianismo: «el iconoclasta o rompeimágenes es un estilita que se erige a sí mismo en imagen, en icono" (p. 66 opus cit.).

15 En un próximo libro provisionalmente titulado Europa, Tema y Variaciones. La Identidad y Variedad Cultural Europea, sostengo que la cultura europea es una síntesis de elementos grecolatinos y eurocristianos, entendiendo por eurocristiano una sinergia de elementos hebreos y grecolatinos como es el calendario eurocristiano (1999 es tanto una fecha europea como cristiana y por tanto eurocristiana, vigente como sistema cultural para ateos, creyentes, euroescépticos y europeistas convencidos. Podrán todas estas facciones o sectas discutir acaloradamente sobre el significado de la identidad cultura europea, pero todos se encuentran velis nolis en el mismo siglo o milenio, que no es el de la sociedad y cultura china).

\section{Bibliografía}

ARDRey, R. (1966): The Territorial Imperative, Glasgow, Fontana/Collins. Aristóteles, (1987): Metafisica (trad. Valentín García Yedra), Madrid, Gredos, $2^{\mathrm{a}}$ ed. 


\section{El cerebro humano aplicado a la creatividad}

Botella Llusiá, José, y Mora, Francisco (coordinadores) (1998): ¿Cómo Funciona el Cerebro?, Universidad de Valladolid, Fundación Duques de Soria.

Damasio, Antonio R. (1996): Descartes' Error, Papermac, London.

DARWIN,Charles Robert (1987): El Origen del Hombre (obra completa), 2 T. (TRAD. Barroso Bonzón), $2^{a}$ ed., Ibéricas.

DawkIns, Richard (1976): The Selfish Gene, Oxford University Press.

Durkнeim, Emile (1988): Reglas del Método Sociológico (trad. Santiago Noriega González) Alianza, Madrid.

Esopo, (1993) Fabulas, Editorial Gredos, Madrid.

Evans-Pritchard, E.E. (1987): Historia del Pensamiento Antropológico, Cátedra, Madrid. Freud, Sigmund (1973): Obras Completas (trad. Luis López-Ballesteros), $3^{\mathrm{a}}$ ed., Biblioteca Nueva.

GEERTZ, Clifford (1989): La Interpretación de las Culturas, Gedisa, Barcelona.

Grout D.J. y PAPISCA c.V. (1984): Historia de la Música Occidental, 2 Alianza, Madrid. HuIzinga, J. (1987) Homo Ludens, Alianza, Madrid.

JAmes, William (1952): The Principles of Psychology, Great Books of the Western World London.

JÁUREGUI, José A. (1998): Cerebro y Emociones:El Ordenador Emocional. Maeva, Madrid. Leibntz, G.W. (1983): Monadología, Discurso de metafísica, Profesión de fe del filósofo (trad. De Manuel Fuentes/Alfonso Castaño/Francisco de P. Samaranch), Orbis.

Lorenz, Konrad (1989): Sobre la Agresión. El Pretendido mal (trad. Félix Blanco), $7^{a}$ ed., Siglo XXI, Madrid.

Madariaga, Salvador de (1979): Retrato de un hombre de pie. Espasa-Calpe, Madrid. Orwell G. (1973) Rebelión en la Granja, Destino, Barcelona.

Penrose, Roger (1991): La Nueva mente del Emperador. Mondadori, Madrid.

Platon (1976): Diálogos. Espasa-Calpe, Madrid.

THorPE; W.H. (1963):Learning and Instinct in animals, Methuen, London.

Unamuno,Miguel de (1976): Del Sentimiento Trágico de la Vida. Espasa-Calpe, Madrid.

Wilson, Edward O.(1980): Sociobiología (trad. Ramón Navarro) Omega, Barcelona. 